\title{
EMERGÊNCIA DE PLANTAS DANINHAS EM CANAVIAIS INFLUENCIADA POR DIFERENTES DOSES DE CALCÁRIO
}

\author{
MORO, Eduardo ${ }^{1}$ \\ AZANIA, Carlos Alberto Mathias ${ }^{2}$ \\ AZANIA, Andréa Aparecida de Padua Mathias ${ }^{3}$ \\ SCHIAVETTO, Ana Regina ${ }^{4}$ \\ ADRIANO, Rodrigo $\mathrm{Cabral}^{5}$ \\ SOARES, Ricardo Oliveira ${ }^{6}$
}

RESUMO: A hipótese de que alterações químicas no solo, proporcionadas pela aplicação de doses de calcário prejudicam o desenvolvimento de algumas infestantes e beneficiam outras foi sugerida. Para tanto, estudou-se o efeito de doses de calcário aplicadas ao solo sobre a emergência e desenvolvimento inicial das espécies de plantas daninhas monocotiledôneas e dicotiledôneas infestantes de canaviais. Foram instalados dois experimentos em delineamento experimental inteiramente casualizado, em quatro repetições, ambos em vasos $(3 \mathrm{~L})$ e em casa de vegetação. Os esquemas fatoriais foram 5 x 4 e 6 x 4, sendo alocadas no primeiro fator as espécies monocotiledôneas (Brachiaria decumbens, Brachiaria brizantha, Panicum maximum, Digitaria horizontalis, Rottboellia exaltata) para o primeiro experimento e dicotiledôneas (Ipomoea quamoclit, Ipomoea grandifolia, Ipomoea purpurea, Ipomoea nil, Merremia aegyptia, Euphorbia heterophylla) no segundo experimento; o segundo fator representou as doses de calcário $\left(0,800,1600\right.$ e $\left.3200 \mathrm{~kg} \mathrm{ha}^{-1}\right)$ para ambos os experimentos. Avaliou-se até o $15^{\circ}$ dia após semeadura (DAS) o número de plantas emergidas, posteriormente, calculou-se a emergência (\%) e o índice de velocidade de emergência; aos 49 DAS aferiu-se a altura e o número de folhas, massa seca da raiz e parte aérea das plantas. A hipótese inicial foi confirmada como verdadeira, pois a dose de $3200 \mathrm{~kg} \mathrm{ha}^{-1}$ de calcário estimulou a emergência e prejudicou o acúmulo de massa seca nas plantas monocotiledôneas, enquanto que nas dicotiledôneas a dose máxima foi indiferente na emergência, mas prejudicou o acúmulo de massa seca.

Palavras-chave: $\mathrm{pH}$. Plantas daninhas. Cana-de-açúcar.

\section{WEED EMERGENCE IN SUGARCANE INFLUENCED BY DIFFERENT DOSES OF LIME}

SUMMARY: The hypothesis that the chemical changes on the soil, provided by the application of lime rates damage the development of some weeds and other benefits was suggested. Therefore, was studied the effect of lime rates applied to the soil on the emergence and early growth of weed species monocotyledons and dicotyledons present sugarcane. Two experiments were established in randomized entirely design, with four replications both in pots $(3 \mathrm{~L})$ and in a greenhouse. The schemes were factorial $5 \times 4$ and $6 \times 4$, the first factor was placed monocotyledons species (Brachiaria decumbens, Brachiaria brizantha, Panicum maximum, Digitaria horizontalis, Rottboellia exaltata) for the first experiment and dicotyledons (Ipomoea quamoclit, Ipomoea grandifolia, Ipomoea purpurea, Ipomoea nil, Merremia aegyptia, Euphorbia heterophylla) in the second experiment; the second factor represented lime rates $(0,800,1600$ and $3200 \mathrm{~kg}$ ha-1). It was evaluated until the 15 th day after sowing (DAS) the number of plants emerged and estimated emergence (\%) and the emergency speed index; to the 49 (DAS) was evaluated height, leaf number, dry weight of roots and shoots of plants. The initial hypothesis was confirmed as true because the lime rate of $3200 \mathrm{~kg} \mathrm{ha}^{-1}$ stimulated the emergence and damaged the dry mass accumulation of the plants monocotyledons, while that in the dicotyledons the rate maximum was indifferent to in the emergency, but also damaged the accumulation of dry mass.

\footnotetext{
${ }^{1}$ Graduando em Engenharia Agronômica, Bolsista PIBIC no Centro de Cana, Instituto Agronômico

${ }^{2}$ Pesquisador Científico, Centro de Cana, Instituto Agronômico, Ribeirão Preto, SP

${ }^{3}$ Pós-doutoranda, Centro de Cana, Ribeirão Preto, SP

${ }^{4}$ Doutoranda em Genética e Melhoramento de Plantas, Unesp, Jaboticabal, Departamento de Ciências Exatas, Jaboticabal, SP

${ }^{5}$ Mestrando em Agricultura Tropical e Subtropical no Instituto Agronômico, Centro de Cana, Ribeirão Preto

${ }^{6}$ Graduando em Engenharia Agronômica, Bolsista PIBIC, Centro de Cana, Ribeirão Preto, SP
} 
Keywords: pH. Weed. Sugarcane.

\section{INTRODUÇÃO}

A maior preocupação dos produtores de cana de açúcar é manter a área cultivada com baixa infestação de plantas daninhas, minimizando assim os prejuízos causados ao desenvolvimento e produtividade das culturas (KUVA et al., 2003). Contudo, seu manejo não pode ser focado unicamente sobre uma única prática agrícola, mas na integração de medidas culturais, mecânicas, físicas e químicas (HARKER et al., 2009).

A preferência pelo controle químico na cultura, segundo Mascarenhas et al. (1995), é devido à praticidade, eficiência dos produtos e do alto rendimento operacional. Entretanto, a consequiência do uso inadequado de herbicidas prejudica principalmente os recursos ambientais, devido contaminar lençóis freáticos (PANG et al., 2000), cursos d'água (BORTOLUZZI, 2005) ou até mesmos outras culturas (SILVA et al., 1999), quando próximas aos canaviais tratados.

Alternativas que minimizem o uso de herbicidas podem ser encontradas em estudos relacionados à biologia das plantas daninhas. Gravena et al. (2004) propuseram os estudos entre a interação das plantas daninhas com o ambiente, podendo esse conhecimento ser associado a outros manejos e minimizar o uso de herbicidas. Nesse contexto, a calagem pode suprimir, prejudicar ou favorecer espécies daninhas nas áreas agrícolas, embora essas constatações sejam baseadas em observações de campo, sendo escassas as informações na literatura.

Contudo, o cultivo da cana-de-açúcar abrange desde solos férteis aos de baixa fertilidade, que, geralmente, também são acompanhados de acidez do solo (GARCIA et al., 2011). Esses solos quando corrigidos e associados às condições climáticas favoráveis adequadas proporcionam ambientes de produção que favorecem o desenvolvimento da cultura (MAULE; MAZZA; MARTHA JUNIOR, 2001). Mas, simultaneamente selecionam as espécies daninhas deixando as de maior capacidade competitiva, a exemplo de Panicum maximum (KUVA et al., 2003), Brachiaria spp. (KUVA et al., 2001), Ipomoea spp. (SILVA et al., 2009), Rottboelia exaltata (BIANCO; BARBOSA JUNIOR PITELLI, 2004).

$\mathrm{Na}$ prática, espécies de Ipomoea spp. e Merremia spp., vêm se destacando por causarem diminuição na produtividade de cana-de-açúcar, especialmente em áreas de cana colhida sem prévia queima do canavial (AZANIA et al., 2002). Outros exemplos são as espécies de Euphorbia heterophylla (MONQUERO et al., 2007) e Digitaria spp (DIAS et al., 2007) que também têm causado prejuízos à cultura.

Segundo Favreto; Medeiros (2006) os indivíduos da flora daninha são selecionados simultaneamente à medida em que as condições climáticas interam-se com as edáficas. No entanto, uma importante prática agrícola é a calagem, mas são poucos os estudos abordando o comportamento de plantas daninhas frente ao manejo de solo com essa atividade.

Considerando-se essas observações, sugeriu-se a hipótese de que a alteração na química do solo devido à aplicação de calcário prejudique o desenvolvimento inicial de algumas espécies daninhas e favoreça de outras nos canaviais. Assim, objetivou-se estudar o efeito de doses de calcário aplicadas ao solo sobre a emergência e desenvolvimento inicial das espécies de plantas daninhas monocotiledôneas e dicotiledôneas infestantes de canaviais.

Nucleus, v.9, n.2, out.2012 


\section{MATERIAL E MÉTODOS}

Foram conduzidos dois experimentos, em casa de vegetação, no período de agosto de 2010 a março de 2011 no Centro de Cana, pertencente ao Instituto Agronômico, na cidade de Ribeirão Preto, estado de São Paulo, localizado a $621 \mathrm{~m}$ de altura em relação ao nível do mar, avaliando-se, no primeiro, as espécies monocotiledôneas e no segundo, as dicotiledôneas.

Em ambos os experimentos utilizou-se o delineamento inteiramente casualizado em esquema fatorial com 4 repetições. Os esquemas fatoriais foram $5 \times 4$ e $6 \times 4$, sendo alocadas no primeiro fator as espécies monocotiledôneas (B. decumbens, B. brizantha, P. maximum, D. horizontalis e R. exaltata) para o primeiro experimento e dicotiledôneas (I. quamoclit, I. grandifolia, I. purpurea, I. nil, M. aegyptia e E. heterophylla) no segundo experimento; o segundo fator representou as doses de calcário $(0,800,1600 \mathrm{e}$ $3200 \mathrm{~kg} \mathrm{ha}^{-1}$ ) para ambos os experimentos. A escolha das espécies foi devido serem infestantes de difícil controle principalmente em cana-de-açúcar.

As sementes das plantas daninhas foram adquiridas em empresa especializada e para cada espécie foram contadas previamente 100 unidades, acondicionadas em saquinhos de papel e posteriormente semeadas nas parcelas. A quantidade de sementes foi calculada para proporcionar a emergência de no mínimo 25 plantas, de acordo com o teste de germinação do fornecedor.

O substrato utilizado foi terra de classe textural muito argilosa (64\% argila, $12 \%$ areia e $24 \%$ silte) coletada em barranco, cujas características químicas encontram-se na Tabela 1. A terra foi previamente peneirada, corrigida com calcário, conforme os tratamentos propostos pelo delineamento e utilizada ao preenchimento das unidades experimentais.

Tabela 1. Características químicas da terra utilizada no preenchimento das unidades experimentais.

\begin{tabular}{c|cccccccc}
\hline \multirow{2}{*}{$\begin{array}{c}\text { Doses } \\
\left(\mathrm{kg} \mathrm{ha}^{-1}\right)\end{array}$} & p.H. & M.O. & P res. & $\mathrm{K}^{+}$ & $\mathrm{Ca}^{+2}$ & $\mathrm{Mg}^{+2}$ & $\mathrm{SB}$ & $\mathrm{V}$ \\
\cline { 2 - 9 } & $\left(\mathrm{CaCl}^{-2}\right)$ & $\left(\mathrm{g} \mathrm{dm}^{-3}\right)$ & $\left(\mathrm{mg} \mathrm{dm}^{-3}\right)$ & & $\left(\mathrm{mmol}_{\mathrm{c}} \mathrm{dm}^{-3}\right)$ & & $(\%)$ \\
\hline $0^{1}$ & 5,2 & 27 & 11 & 1,20 & 13,25 & 5,81 & 20,26 & 39,52 \\
\hline $800^{*}$ & 6,1 & 28 & 17 & 1,69 & 32,09 & 16,48 & 50,25 & 67,68 \\
\hline $1600^{*}$ & 6,5 & 29 & 20 & 1,37 & 32,67 & 18,14 & 52,18 & 74,35 \\
\hline $3200^{*}$ & 6,8 & 26 & 17 & 1,63 & 27,53 & 19,16 & 54,32 & 79,51 \\
\hline
\end{tabular}

Análise realizada no laboratório DMLab, Ribeirão Preto-SP; ${ }^{1}$ análise preliminar; *análise após 25 dias de reação.

Para preparo da terra foram acrescidas as quantidades de calcário, realizada a homogeneização, acondicionada em vasos (3 L) e em casa de vegetação em 28/10/2010. O calcário utilizado foi do tipo dolomítico calcinado com granulometria de $0,30 \mathrm{~mm}$.

O material estava constituído por $48 \%$ de óxido de cálcio $(\mathrm{CaO})$ e $16 \%$ de óxido de magnésio $(\mathrm{MgO})$, que confere poder de neutralização de 125,6 e poder relativo de neutralização total de 124 . As doses de calcário foram calculadas a partir da dose recomendada, com base na análise de solo inicial, tomando-se como referência a recomendação de Espironelo (1999) para a cultura da cana-de-açúcar, devido às espécies serem representativas desse agroecossistema. Após o tempo de reação (25 dias) amostras de cada tratamento foram submetidas à análise química do solo (Tabela 1).

As sementes de plantas daninhas foram semeadas em 24/01/2011 e contado diariamente o número de plântulas emergidas até ao $15^{\circ}$ dia da semeadura. Os dados foram utilizados ao cálculo da porcentagem 
de emergência (\%emergência $=\left(n^{\circ}\right.$ de plântulas emergidas até ao $15^{\circ}$ dia $/ n^{\circ}$ sementes semeadas $\left.) * 100\right)$ e o índice de velocidade de emergência (IVE), conforme Maguire (1962).

Em 14/02/2011 procedeu-se ao desbaste, deixando 3 plantas por vaso, as quais tiveram avaliadas altura, número de folhas, o comprimento, massa seca da raiz e parte aérea aos 49 dias após a semeadura (DAS). A altura foi aferida medindo-se o comprimento em centímetros da distância entre o colo e o ápice; para o número de folhas contou-se todas as folhas de cada planta; para massa seca da parte aérea e raiz o conteúdo de cada vaso foi colocado sobre peneira e lavado para remoção da terra, as raízes recuperadas foram cortadas na base do solo e lavadas, após secagem em estufa até peso constante.

As variáveis foram submetidas à análise de variância, conforme delineamento proposto utilizandose do teste $\mathrm{F}$ e as médias foram comparadas pelo teste Tukey a $5 \%$.

\section{RESULTADOS E DISCUSSÃO}

\section{Experimento com plantas daninhas monocotiledôneas}

A adição de $3200 \mathrm{~kg} \mathrm{ha}^{-1}$ de calcário em relação à terra não tratada elevou o pH em 30,77\% (5,2

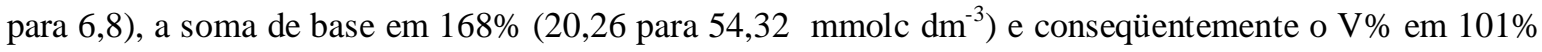
(39,52 para 79,51), conforme a Tabela 1.

As espécies de $P$. maximum e $B$. decumbens foram as mais beneficiadas pelas diferentes doses de calcário por apresentarem as maiores porcentagens de emergência (86,68 e 85,81\%) acompanhadas dos maiores IVE $(13,57$ e 13,26), respectivamente. Para $R$. exaltata e $D$. horizontalis a emergência foi próxima a $50 \%$ com IVE não superando 8,90 . B. brizantha apresentou a emergência pouco estimulada porque foi inferior a 28\%, além do menor IVE (4,54), conforme a Tabela 2.

Segundo Yamashita et al. (2009) a tolerância às variações de pH do meio em que as plantas germinam pode ser variável de acordo com a espécie, por ser uma característica intrínseca às espécies. O conhecimento desse aspecto assume papel importante no entendimento da dinâmica populacional das espécies, principalmente porque a habilidade competitiva das espécies de plantas daninhas para com a cultura pode variar com o pH do solo (WEAVER; HAMILL, 1985). Quanto ao IVE, O'Donovan et al. (2000) relataram que as espécies que apresentam o maior IVE, sobressaíram perante espécies de menor IVE, assim, constatando que cultivares de cevada com maior IVE competiram vantajosamente com Avena fatua.

Tabela 2. Efeito da aplicação de doses de calcário, em diferentes plantas daninhas monocotiledôneas sobre a porcentagem de emergência e índice de velocidade de emergência (IVE) obtidas em 15 dias após semeadura. Ribeirão Preto, 2011

(Continua)

\begin{tabular}{lllll}
\hline Tratamentos & \multicolumn{2}{l}{ \% Emergência } & \multicolumn{2}{l}{ IVE } \\
\hline Espécies (A) & orig & Transf & Orig & Transf $^{2 /}$ \\
B. decumbens & 85,81 & $72,27 \mathrm{a}$ & 13,26 & $3,62 \mathrm{a}$ \\
B. brizantha & 27,43 & $31,94 \mathrm{~d}$ & 4,54 & $2,32 \mathrm{c}$ \\
P. maximum & 86,68 & $74,07 \mathrm{a}$ & 13,57 & $3,79 \mathrm{a}$ \\
D. horizontalis & 45,52 & $42,96 \mathrm{c}$ & 5,55 & $2,55 \mathrm{c}$ \\
R. exaltata & 56,93 & $49,60 \mathrm{~b}$ & 8,90 & $3,13 \mathrm{~b}$ \\
\hline Doses $(\mathbf{B})\left({\left.\mathrm{kg} . \mathrm{ha}^{-1}\right)}^{-1}\right.$ & & & & \\
0 & 61,45 & $54,28 \mathrm{~b}$ & 10,26 & $3,31 \mathrm{a}$ \\
800 & 57,40 & $51,55 \mathrm{~b}$ & 8,12 & $2,92 \mathrm{~b}$ \\
1600 & 56,80 & $50,50 \mathrm{~b}$ & 8,30 & $2,97 \mathrm{~b}$ \\
3200 & 66,25 & $60,34 \mathrm{a}$ & 9,34 & $3,13 \mathrm{ab}$ \\
& & & &
\end{tabular}

Nucleus, v.9, n.2, out.2012 
Tabela 2. Efeito da aplicação de doses de calcário, em diferentes plantas daninhas monocotiledôneas sobre a porcentagem de emergência e índice de velocidade de emergência (IVE) obtidas em 15 dias após semeadura. Ribeirão Preto, 2011

(Conclusão)

\begin{tabular}{lll}
\hline Espécies (A) & $124,76^{* *}$ & $51,58^{* *}$ \\
Doses (B) & $8,89 * *$ & $4,89 * *$ \\
AXB & $6,82 * *$ & $1,03 \mathrm{~ns}$ \\
CV $(\%)$ & 12,20 & 11,59 \\
dms(A) & 6,57 & 0,35 \\
dms(B) & 5,53 & 0,29 \\
\hline
\end{tabular}

${ }^{1 /}$ - dados transformados em arc seno $\sqrt{\mathrm{x}}+1 ;{ }^{2 /}$ dados transformados em $\sqrt{\mathrm{x}}+1$; Orig - dados originais; $*$ significativo a $5 \%$ de probabilidade; ** significativo a $1 \%$ de probabilidade; ns - não significativo.

Especificamente a espécie de $B$. decumbens no desdobramento da interação Espécies $\mathrm{x}$ doses $(\mathrm{AxB})$ apresentou a emergência mais estimulada pelas doses de calcário, a menor e maior dose aumentaram-na em 38,24\%; enquanto que para $P$. maximum a emergência foi inibida (21\%) pelas doses intermediárias ( 800 e $1600 \mathrm{~kg} \mathrm{ha}^{-1}$ ) e indiferentes na maior e menor dose (Tabela 3). Entretanto, na média, a espécie ainda apresentou elevado percentual de emergência (Tabela 2). Já, para $D$. horizontalis e $R$. exaltata a variável foi indiferente para qualquer dose utilizada.

Tabela 3. Desdobramento da interação espécies $x$ doses $(\mathrm{AxB})$ para porcentagem de emergência de plantas daninhas monocotiledôneas aos 15 dias após semeadura influenciadas por diferentes doses de calcário. Ribeirão Preto, 2011.

\begin{tabular}{|c|c|c|c|c|}
\hline \multirow{2}{*}{$\begin{array}{c}\text { Espécies } \\
\text { (A) }\end{array}$} & \multicolumn{4}{|c|}{$\begin{array}{c}\text { Doses (B) } \\
\mathrm{kg} \mathrm{ha}^{-1}\end{array}$} \\
\hline & 0 & 800 & 1600 & 3200 \\
\hline Brachiaria decumbens & $\begin{array}{c}56,21 \mathrm{Bb} \\
(68,00)\end{array}$ & $\begin{array}{c}79,35 \mathrm{Aa} \\
(94,00)\end{array}$ & $\begin{array}{c}70,69 \mathrm{Aa} \\
(87,25)\end{array}$ & $\begin{array}{c}82,83 \mathrm{Aa} \\
(94,00)\end{array}$ \\
\hline Brachiaria brizantha & $\begin{array}{c}39,64 \mathrm{Ac} \\
(39,75)\end{array}$ & $\begin{array}{c}26,96 \mathrm{Bd} \\
(19,75)\end{array}$ & $\begin{array}{c}28,93 \mathrm{ABd} \\
(22,50)\end{array}$ & $\begin{array}{c}32,44 \mathrm{Abc} \\
(27,50)\end{array}$ \\
\hline Panicum maximum & $\begin{array}{c}82,40 \mathrm{Aa} \\
(96,00)\end{array}$ & $\begin{array}{c}61,69 \mathrm{Bb} \\
(75,75)\end{array}$ & $\begin{array}{c}62,18 \mathrm{Bab} \\
(75,00)\end{array}$ & $\begin{array}{c}90,00 \mathrm{Aa} \\
(100,00)\end{array}$ \\
\hline Digitaria horizontalis & $\begin{array}{c}45,86 \mathrm{Abc} \\
(50,50)\end{array}$ & $\begin{array}{c}38,75 \text { Acd } \\
(38,30)\end{array}$ & $\begin{array}{c}\text { 40,52 Acd } \\
(41,30)\end{array}$ & $\begin{array}{c}46,72 \mathrm{Ab} \\
(52,00)\end{array}$ \\
\hline Rottboellia exaltata & $\begin{array}{c}47,30 \mathrm{Abc} \\
(53,00)\end{array}$ & $\begin{array}{c}51,00 \mathrm{Abc} \\
(59,25)\end{array}$ & $\begin{array}{c}50,20 \mathrm{Abc} \\
(58,00)\end{array}$ & $\begin{array}{c}49,90 \mathrm{Ab} \\
(57,50)\end{array}$ \\
\hline
\end{tabular}

Dados transformados em arc seno $\sqrt{ } \mathrm{x}+1$ acompanhados das letras do teste de Tukey a 5\%; Letras maiúsculas compara-se nas linhas e as minúsculas nas colunas; dados entre parênteses correspondem aos originais.

Segundo Reddy; Dunn (1987), a acidez dos solos está entre os fatores que mais afetam o desenvolvimento das espécies de plantas daninhas. Essa evidência pode também ser observada logo após o estabelecimento inicial, ao constatar que as maiores doses de calcário prejudicaram a altura e o número de 
folhas das plantas estudadas (Tabela 4).

A espécie de $B$. decumbens nas doses de 800 e $1600 \mathrm{~kg} \mathrm{ha}^{-1}$ (pH do solo entre 6,1 a 6,5, respectivamente), apresentou a emergência das plantas estimuladas até aos 15 DAS (Tabela 3), sem prejuízo sobre o número de folhas (Tabela 4) e altura (Tabela 5). Observou-se que a espécie somente pode ter o desenvolvimento contido em faixas de $\mathrm{pH}$ do solo a partir de $6,8\left(3200 \mathrm{~kg} \mathrm{ha}^{1}\right)$. Como a maioria dos canaviais são cultivados em solos com faixa de $\mathrm{pH}$ de até 6,5, a calagem não consiste em um artifício que minimize o estabelecimento da espécie.

Para $P$. maximum e $B$. brizantha, nas mesmas doses e faixa de $\mathrm{pH}$, a calagem minimizou o número de plantas, visto pela porcentagem de emergência (Tabela 3), mas não interferiu no número de folhas (Tabela 4) e altura (Tabela 5). O ocorrido permite inferir que a calagem pode minimizar a população dessas espécies nos canaviais, mas não prejudicar o estabelecimento e posterior desenvolvimento. Esses resultados corroboram com Souza Filho, Veloso e Gama (2000), ao observarem a que apesar de $B$. brizantha apresentar tolerância à solos ácidos, a medida em que se neutralizou o solo, a planta apresentou melhor desenvolvimento.

$R$. exaltata além de não ter o estabelecimento prejudicado, visto a porcentagem de emergência (Tabela 3), a altura de suas plantas também não foi prejudicada pelas doses de calcário (Tabela 5). O resultado elucidou que a espécie pode se estabelecer e desenvolver em solos com diferentes características químicas, abrangendo ampla faixa de pH (5,2 a 6,8) e V\% (39,52 a 79,51\%), de acordo com as análises do solo expostas na Tabela 1. A adaptabilidade da espécie em solos com características químicas similares aos canaviais pode explicar a agressividade.

A dose de calcário de $3200 \mathrm{~kg} \mathrm{ha}^{-1}$ sobre $D$. horizontalis, embora tenha sido indiferente ao estabelecimento da espécie, observado pelos valores de emergência (Tabela 3), prejudicou a altura das plantas a partir da dose de $1600 \mathrm{~kg} \mathrm{ha}^{-1}$ (Tabela 5) sem interferir no número de folhas (Tabela 4). Possivelmente, em canaviais a espécie poderá apresentar-se com alturas menores, porém, o número de indivíduos não será reduzido. Machado et al. (2006) estudaram características de crescimento para $D$. insularis e observaram o lento crescimento inicial até aos 45 dias após a emergência.

Tabela 4. Efeito da aplicação de doses de calcário, em diferentes plantas daninhas monocotiledôneas sobre a altura e número de folhas obtidos aos 49 dias após semeadura. Ribeirão Preto, 2011

\begin{tabular}{ccccc}
\hline Tratamentos & \multicolumn{2}{c}{ Altura 49 DAA } & \multicolumn{2}{c}{$\mathbf{N}^{\mathbf{}}$ de folhas 49 DAA } \\
\hline Espécies (A) & orig & Transf & orig & Transf \\
B. decumbens & 5,23 & $2,43 \mathrm{~b}$ & 3,69 & $2,14 \mathrm{ab}$ \\
B. brizantha & 4,41 & $2,31 \mathrm{~b}$ & 3,23 & $2,04 \mathrm{~b}$ \\
P. maximum & 4,30 & $2,26 \mathrm{~b}$ & 3,35 & $2,07 \mathrm{~b}$ \\
D. horizontalis & 15,26 & $3,96 \mathrm{a}$ & 4,40 & $2,31 \mathrm{a}$ \\
R. exaltata & 5,90 & $2,60 \mathrm{~b}$ & 1,96 & $1,70 \mathrm{c}$ \\
\hline
\end{tabular}

(Continua)

Doses (B) $\left(\mathrm{kg}_{\mathrm{hha}}{ }^{-1}\right)$

$\begin{array}{ccccc}0 & 7,98 & 2,90 \mathrm{a} & 3,68 & 2,15 \mathrm{a} \\ 800 & 8,93 & 3,00 \mathrm{a} & 3,47 & 2,10 \mathrm{ab} \\ 1600 & 5,62 & 2,51 \mathrm{~b} & 3,10 & 2,00 \mathrm{ab} \\ 3200 & 5,55 & 2,44 \mathrm{~b} & 3,05 & 1,97 \mathrm{~b}\end{array}$


Tabela 4. Efeito da aplicação de doses de calcário, em diferentes plantas daninhas monocotiledôneas sobre a altura e número de folhas obtidos aos 49 dias após semeadura. Ribeirão Preto, 2011

(Conclusão)

\begin{tabular}{ccc}
\hline Espécies (A) & $54,55 * *$ & $17,73 * *$ \\
Doses (B) & $10,38 * *$ & $3,09 *$ \\
AXB & $2,49 * *$ & $0,81 \mathrm{NS}$ \\
CV (\%) & 14,16 & 10,27 \\
dms(A) & 0,38 & 0,21 \\
dms(B) & 0,32 & 0,17
\end{tabular}

Transf, - dados transformados em $\sqrt{\mathrm{x}+1}$; Orig - dados originais; * significativo a 5\% de probabilidade; ** significativo a $1 \%$ de probabilidade; ns - não significativo

Panicum maximum foi a espécie que apresentou o menor acúmulo de massa seca, nas raízes $(0,27$ g) e parte aérea $(0,33 \mathrm{~g})$; para as demais, os valores não diferiram estatisticamente (Tabela 6). Esses resultados corroboram com Ruiz, Neto e Santana (1995) ao observarem a capacidade das espécies monocotiledôneas em desenvolver-se em solos ácidos e de baixa fertilidade.

Tabela 5. Desdobramento da interação entre espécies e doses $(\mathrm{AxB})$ para altura $(\mathrm{cm})$ de plantas daninhas monocotiledôneas medida aos 49 dias após semeadura influenciadas por diferentes doses de calcário. Ribeirão Preto, 2011.

\begin{tabular}{|c|c|c|c|c|}
\hline \multirow{2}{*}{$\begin{array}{c}\text { Espécies } \\
\text { (A) }\end{array}$} & \multicolumn{4}{|c|}{$\begin{array}{c}\text { Doses (B) } \\
\text { kg ha }^{-1}\end{array}$} \\
\hline & 0 & 800 & 1600 & 3200 \\
\hline B.decumbens & $\begin{array}{c}2,66 \mathrm{Ab} \\
(6,13)\end{array}$ & $\begin{array}{c}2,77 \mathrm{Ab} \\
(7,00)\end{array}$ & $\begin{array}{c}2,53 \mathrm{Ab} \\
(5,42)\end{array}$ & $\begin{array}{c}1,78 \mathrm{Bb} \\
(2,38)\end{array}$ \\
\hline B.brizantha & $\begin{array}{c}2,53 \mathrm{Ab} \\
(5,42)\end{array}$ & $\begin{array}{c}2,38 \mathrm{Ab} \\
(4,71)\end{array}$ & $\begin{array}{c}2,22 \mathrm{Ab} \\
(3,96)\end{array}$ & $\begin{array}{c}2,12 \mathrm{Ab} \\
(3,54)\end{array}$ \\
\hline P.maximum & $\begin{array}{c}2,27 \mathrm{Ab} \\
(4,21)\end{array}$ & $\begin{array}{c}2,38 \mathrm{Ab} \\
(4,71)\end{array}$ & $\begin{array}{c}1,90 \mathrm{Ab} \\
(2,67)\end{array}$ & $\begin{array}{c}2,50 \mathrm{Ab} \\
(5,63)\end{array}$ \\
\hline D.horizontalis & $\begin{array}{c}4,26 \mathrm{Aa} \\
(17,29)\end{array}$ & $\begin{array}{c}4,72 \mathrm{Aa} \\
(21,79)\end{array}$ & $\begin{array}{c}3,45 \mathrm{Ba} \\
(11,04)\end{array}$ & $\begin{array}{c}3,39 \mathrm{Ba} \\
(10,92)\end{array}$ \\
\hline R.exaltata & $\begin{array}{c}2,79 \mathrm{Ab} \\
(6,83)\end{array}$ & $\begin{array}{c}2,72 \mathrm{Ab} \\
(6,46)\end{array}$ & $\begin{array}{c}2,44 \mathrm{Ab} \\
(5,00)\end{array}$ & $\begin{array}{c}2,44 \mathrm{Ab} \\
(5,29)\end{array}$ \\
\hline
\end{tabular}

Transf, - dados transformados em $\sqrt{\mathrm{x}+1}$; Orig - dados originais; letras maiúsculas compara-se nas linhas e as minúsculas nas colunas.

No final dos 49 dias da instalação do experimento pode-se observar que as doses de calcário, particularmente as de $800 \mathrm{e} 1600 \mathrm{~kg} \mathrm{ha}^{-1}$, beneficiaram $B$. decumbens quanto à porcentagem de emergência e acúmulo de massa seca, mas prejudicaram as plantas de $P$. maximum; reduziram a 
porcentagem de emergência de $B$. brizantha mas não o suficiente para reduzir o acúmulo de massa seca; foram indiferentes na emergência e acúmulo de massa seca das plantas de Rottboellia exaltata e D. horizontalis.

Tabela 6. Efeito da aplicação de doses de calcário, em diferentes plantas daninhas monocotiledôneas sobre a massa seca da parte aérea (MSPA) e massa seca da raiz (MSR) obtidas aos 49 dias após semeadura. Ribeirão Preto, 2011

\begin{tabular}{|c|c|c|c|c|}
\hline \multirow{2}{*}{$\begin{array}{l}\text { Tratamentos } \\
\text { Espécies (A) }\end{array}$} & \multicolumn{2}{|c|}{ MSPA (g) } & \multicolumn{2}{|c|}{$\operatorname{MSR}(\mathrm{g})$} \\
\hline & orig & transf & orig & $\operatorname{transf}$ \\
\hline B. decumbens & 0,41 & $1,17 a b$ & 0,59 & $1,25 \mathrm{a}$ \\
\hline B. brizantha & 0,49 & $1,21 \mathrm{a}$ & 0,71 & $1,30 \mathrm{a}$ \\
\hline P. maximum & 0,33 & $1,15 \mathrm{~b}$ & 0,27 & $1,12 \mathrm{c}$ \\
\hline D. horizontalis & 0,46 & $1,20 a b$ & 0,42 & $1,19 \mathrm{~b}$ \\
\hline R. exaltata & 0,43 & $1,19 a b$ & 0,62 & $1,26 \mathrm{a}$ \\
\hline \multicolumn{5}{|l|}{ Doses (B) $\left(\mathrm{kg} \cdot \mathrm{ha}^{-1}\right)$} \\
\hline 0 & 0,61 & $1,26 \mathrm{a}$ & 0,78 & $1,32 \mathrm{a}$ \\
\hline 800 & 0,50 & $1,22 \mathrm{a}$ & 0,59 & $1,25 \mathrm{~b}$ \\
\hline 1600 & 0,29 & $1,13 \mathrm{~b}$ & 0,33 & $1,15 \mathrm{c}$ \\
\hline 3200 & 0,29 & $1,13 \mathrm{~b}$ & 0,40 & $1,17 \mathrm{c}$ \\
\hline Espécies (A) & & $3,26 *$ & & $19,44 * *$ \\
\hline Doses (B) & & $27,32 * *$ & & $32,63 * *$ \\
\hline AXB & & $1,13 \mathrm{~ns}$ & & $1,88 \mathrm{~ns}$ \\
\hline $\mathrm{CV}(\%)$ & & 4,63 & & 5,13 \\
\hline $\operatorname{dms}(\mathrm{A})$ & & 0,05 & & 0,06 \\
\hline $\mathrm{dms}(\mathrm{B})$ & & 0,04 & & 0,05 \\
\hline
\end{tabular}

Transf. - dados transformados em $\sqrt{\mathrm{x}+1}$; Orig - dados originais; * significativo a 5\% de probabilidade; ** significativo a $1 \%$ de probabilidade; ns - não significativo.

\section{Experimento com plantas daninhas dicotiledôneas}

E. heterophylla apresentou porcentagem de emergência de 63,87\%, sendo o maior valor e diferindo entre as espécies estudadas. As sementes desta espécie não necessitam de luz para germinarem, e além do mais, são capazes de germinar em solos extremamente ácidos à alcalinos (BRECKE, 1995; BRECKE; TOBOLA, 1996).

Quanto à emergência das outras espécies, verificou-se que M. aegyptia, I. quamoclit e I. purpurea tiveram $34,50 \%, 32,31 \%$ e $27,05 \%$ respectivamente e $M$. aegyptia apresentou o maior IVE $(11,72)$ diferindo das demais. Já I.nil e I. grandifolia tiveram a porcentagem de emergência e IVE menos influenciados pela aplicação das doses de calcário (Tabela 7). As espécies que provavelmente terão melhor habilidade em competir com a cultura de interesse serão as que apresentarem melhor IVE (BALBINOT JR. et al., 2001). Neste caso, o maior valor de IVE de Merremia aegyptia faz da espécie uma competidora mais eficiente, uma vez que segundo Martins et al., (2010) é mais exigente em 
macronutrientes do que I. nil e I. quamoclit, com maior habilidade competitiva, e conseqüentemente interferindo mais intensamente no desenvolvimento das culturas agrícolas.

Tabela 7. Efeito da aplicação de doses de calcário, em diferentes plantas daninhas dicotiledôneas para emergência (\%) e no índice de velocidade de emergência aos 15 dias após a semeadura (DAS), Ribeirão Preto, 2011.

\begin{tabular}{|c|c|c|c|c|}
\hline \multirow{2}{*}{$\begin{array}{l}\text { Tratamentos } \\
\text { Espécies (A) }\end{array}$} & \multicolumn{2}{|c|}{ \% EMERGENCIA } & \multicolumn{2}{|c|}{ IVE } \\
\hline & Orig. & Transf. & Orig. & Transf. \\
\hline I. quamoclit & 32,31 & $35,12 \mathrm{~b}$ & 4,77 & $2,88 \mathrm{bc}$ \\
\hline I. grandifolia & 8,37 & $17,62 \mathrm{~d}$ & 1,29 & $1,72 \mathrm{~d}$ \\
\hline I.purpurea & 27,05 & $32,04 \mathrm{~b}$ & 3,92 & $2,61 \mathrm{c}$ \\
\hline I.nil & 15,56 & $23,78 \mathrm{c}$ & 2,01 & $1,97 \mathrm{~d}$ \\
\hline M.aegyptia & 34,50 & $36,33 \mathrm{~b}$ & 11,71 & $4,22 \mathrm{a}$ \\
\hline E.heterophylla & 63,87 & $53,90 \mathrm{a}$ & 6,38 & $3,17 \mathrm{~b}$ \\
\hline \multicolumn{5}{|l|}{ Doses (B) } \\
\hline 0 & 30,13 & $33,07 \mathrm{a}$ & 7,93 & $2,88 \mathrm{a}$ \\
\hline 800 & 30,13 & $33,03 \mathrm{a}$ & 7,60 & $2,78 \mathrm{ab}$ \\
\hline 1600 & 27,79 & 31,36 a & 6,56 & $2,57 \mathrm{~b}$ \\
\hline 3200 & 33,38 & $35,07 \mathrm{a}$ & 7,85 & $2,81 \mathrm{ab}$ \\
\hline Espécies (A) & & $95,24 * *$ & & $88,59 * *$ \\
\hline Doses (B) & & $2,12 \mathrm{~ns}$ & & $2,85 *$ \\
\hline $\mathrm{AXB}$ & & $1,35 \mathrm{~ns}$ & & $0,88 \mathrm{~ns}$ \\
\hline $\mathrm{CV}(\%)$ & & 15,39 & & 13,81 \\
\hline $\operatorname{dms}(\mathrm{A})$ & & 5,28 & & 0,39 \\
\hline $\mathrm{dms}(\mathrm{B})$ & & 3,87 & & 0,29 \\
\hline
\end{tabular}

Transf. - dados transformados em $\sqrt{\mathrm{x}+1}$; Orig - dados originais; * significativo a 5\% de probabilidade; ** significativo a $1 \%$ de probabilidade; ns - não significativo.

Quanto às doses de calcário aplicadas, não houve diferença para porcentagem de emergência, mas para IVE a dose de $1600 \mathrm{~kg} \mathrm{ha}^{-1}$ proporcionou atraso de 4,5\% comparado a testemunha (Tabela 7). Alguns trabalhos relatam o efeito de $\mathrm{pH}$ para emergência de sementes de plantas daninhas, com espécies que emergem em amplas condições de pH, como Merremia pudica e Ipomoea asarifolia (SOUZA FILHO et al., 2001). Para outras espécies a aplicação do calcário prejudica, como Sollanum sarrachoides (ZHOU; DECKARD; AHRENS, 2005) e outras podem ser classificadas como sensíveis a variação de pH no solo, a exemplo de Emillia sonchifolia (YAMASHITA et al. 2009).

Tabela 8. Efeito da aplicação de doses de calcário, em plantas daninhas dicotiledôneas sobre a altura (cm) e número de folhas aos 49 dias após a semeadura (DAS), Ribeirão Preto, 2011.

(Continua)

Tratamentos Altura 49 DAS Número de folhas 49 DAS

\begin{tabular}{ccccc}
\hline Espécies (A) & Orig & Transf & Orig & Transf \\
I. quamoclit & 9,43 & $3,15 \mathrm{ab}$ & 8,63 & $2,99 \mathrm{a}$ \\
I.grandifolia & 18,41 & $3,05 \mathrm{a}$ & 5,40 & $2,52 \mathrm{ab}$ \\
I.purpurea & 20,21 & $4,42 \mathrm{a}$ & 3,83 & $2,19 \mathrm{~b}$ \\
I.nil & 12,43 & $3,55 \mathrm{~b}$ & 4,31 & $2,29 \mathrm{~b}$ \\
M. aegyptia & 9,71 & $3,24 \mathrm{~b}$ & 3,65 & $2,13 \mathrm{~b}$ \\
E.heterophylla & 11,69 & $3,45 \mathrm{~b}$ & 5,00 & $2,41 \mathrm{~b}$
\end{tabular}

Nucleus, v.9, n.2, out.2012 
Tabela 8. Efeito da aplicação de doses de calcário, em plantas daninhas dicotiledôneas sobre a altura (cm) e número de folhas aos 49 dias após a semeadura (DAS), Ribeirão Preto, 2011. (Conclusão)

\begin{tabular}{ccccc}
\hline Doses $(\mathbf{B})\left(\mathrm{kg}_{\mathrm{hha}}{ }^{-1}\right)$ & & & \\
0 & 11,59 & $3,45 \mathrm{ab}$ & 4,80 & $2,39 \mathrm{a}$ \\
800 & 14,17 & $3,81 \mathrm{a}$ & 5,17 & $2,48 \mathrm{a}$ \\
1600 & 13,45 & $3,59 \mathrm{ab}$ & 5,73 & $2,51 \mathrm{a}$ \\
3200 & 8,94 & $3,07 \mathrm{~b}$ & 4,95 & $2,32 \mathrm{a}$ \\
\hline Espécies (A) & $5,70 * *$ & $7,34 * *$ \\
Doses (B) & $3,37 *$ & $0,79 \mathrm{~ns}$ \\
AXB & $0,69 \mathrm{~ns}$ & $0,32 \mathrm{~ns}$ \\
dms(B) & 0.86 & 0.47 \\
dms(A) & 0.63 & 0.35 \\
CV (\%) & 23,95 & 19,12 \\
\hline
\end{tabular}

Transf, - dados transformados em $\sqrt{\mathrm{x}}+1$; Orig - dados originais; * significativo a $5 \%$ de probabilidade; $* *$ significativo a $1 \%$ de probabilidade; ns - não significativo.

Apesar de I. grandifolia ter apresentado emergência pouco estimulada até os 15 DAS, ao final dos 49 DAS apresentou melhor desenvolvimento que as demais, na ocasião apresentou com $18,41 \mathrm{~cm}$ de altura e 5,4 folhas (Tabela 8). Em relação às doses de calcário, a dose de $3200 \mathrm{~kg} \mathrm{ha}^{-1}$ diminuiu o crescimento das espécies, enquanto a 800 e $1600 \mathrm{~kg} \mathrm{ha}^{-1}$ estimulou o crescimento das plantas.

O acúmulo de massa seca nas raízes variou entre 0,92 e mínimo de 0,21 g, já, na parte aérea, os valores ocorreram de 0,85 a 0,44 g, respectivamente para I. nil e E. heterophylla (Tabela 9). Corroborando com esses resultados, Duarte et al. (2008), verificaram grande capacidade de absorção de nutrientes e acúmulo de massa seca para $I$. nil, principalmente na parte aérea, podendo ser explicado pelo fato de a espécie ser de hábito trepador.

Tabela 9. Efeito da aplicação de doses de calcário, em diferentes plantas daninhas dicotiledôneas para massa seca da parte aérea (MSPA) e massa seca do sistema radicular (MSR) aos 49 dias após a semeadura (DAS). Ribeirão Preto, 2011.

(Continua)

\begin{tabular}{ccccc}
\hline Tratamentos & \multicolumn{2}{c}{ MSPA } & \multicolumn{2}{c}{ MSR } \\
\hline Espécies (A) & orig & transf & orig & transf \\
I. quamoclit & 0,51 & $1,22 \mathrm{c}$ & 0,35 & $1,16 \mathrm{bc}$ \\
I.grandifolia & 0,57 & $1,24 \mathrm{bc}$ & 0,55 & $1,23 \mathrm{ab}$ \\
I.purpurea & 0,81 & $1,34 \mathrm{ab}$ & 0,73 & $1,31 \mathrm{a}$ \\
I.nil & 0,85 & $1,35 \mathrm{a}$ & 0,92 & $1,29 \mathrm{a}$ \\
M.aegyptia & 0,71 & $1,30 \mathrm{abc}$ & 0,58 & $1,25 \mathrm{a}$ \\
E.heterophylla & 0,44 & $1,19 \mathrm{c}$ & 0,21 & $1,10 \mathrm{c}$ \\
\hline Doses (B) & & & & \\
0 & 0,76 & $1,30 \mathrm{a}$ & 0,86 & $1,32 \mathrm{a}$ \\
800 & 0,68 & $1,27 \mathrm{ab}$ & 0,54 & $1,21 \mathrm{~b}$ \\
1600 & 0,82 & $1,31 \mathrm{a}$ & 0,50 & $1,19 \mathrm{~b}$ \\
3200 & 0,52 & $1,22 \mathrm{~b}$ & 0,42 & $1,16 \mathrm{~b}$
\end{tabular}


Tabela 9. Efeito da aplicação de doses de calcário, em diferentes plantas daninhas dicotiledôneas para massa seca da parte aérea (MSPA) e massa seca do sistema radicular (MSR) aos 49 dias após a semeadura (DAS). Ribeirão Preto, 2011.

(Conclusão)

\begin{tabular}{ccc}
\hline Espécies (A) & $6,21 * *$ & $18,41 * *$ \\
Doses (B) & $4,09 * *$ & $20,29 * *$ \\
AXB & $0,86 \mathrm{~ns}$ & $1,80 \mathrm{~ns}$ \\
CV (\%) & 7,95 & 6,06 \\
dms(A) & 0,10 & 0,07 \\
dms(B) & 0,07 & 0,05 \\
\hline
\end{tabular}

Transf. - dados transformados em $\sqrt{\mathrm{x}+1}$; Orig - dados originais; * significativo a $5 \%$ de probabilidade; ** significativo a $1 \%$ de probabilidade; ns - não significativo.

A aplicação de doses de calcário provocou alterações na MSR e MSPA, em especial à $3.200 \mathrm{~kg}$ $\mathrm{ha}^{-1}$, por ter ocasionado perdas em ambas variáveis (Tabela 9). Esses resultados foram contrários aos observados por Oliveira et al. (2009), que ao estudarem a mobilização do calcário no solo por método biológico, descreveram que o crescimento radicular aumenta com a dose aplicada e com o passar do tempo. No entanto, as doses de calcário não prejudicaram a emergência das espécies até aos 15 DAS, mas aos 49 DAS a dose máxima (3200 $\mathrm{kg} \mathrm{ha}^{-1}$ ) foi a que mais interferiu sobre a altura e massa seca das espécies dicotiledôneas.

\section{CONCLUSÃO}

A hipótese inicial foi confirmada como verdadeira, pois a alteração química do solo devido à aplicação de calcário permitiu que a dose de $3200 \mathrm{~kg} \mathrm{ha}^{-1}$ estimulasse a emergência das espécies monocotiledôneas, enquanto que para as dicotiledôneas a dose máxima foi indiferente à variável, com prejuízo para as monocotiledôneas e dicotiledôneas na variável massa seca.

\section{REFERENCIAS}

AZANIA, A. A. P. M. et al. Interferência da palha de cana-de-açúcar (Saccharum spp.) na emergência de espécies de plantas daninhas da família Convolvulaceae. Planta Daninha, v.20, n.2, p.207-212, 2002.

BALBINOT JR., A. A. et al. Velocidade de emergência e crescimento inicial de cultivares de arroz irrigado influenciando a competitividade com as plantas daninhas. Planta daninha, v.19, n.3, p.305-316, 2001.

BIANCO, S.; BARBOSA JUNIOR, A.F.; PITELLI, R.A. Crescimento e nutrição mineral de capimcamalote. Planta daninha, v.22, n.3, p. 375-380, 2004.

BORTOLUZZI, E. C. Caracterização quali-quantitativa de sedimento fluvial oriundo da microbacia hidrográfica Fumageira de Agudo, Rio Grande do Sul, Brasil. Brasília: Bortoluzzi, E. C., 2004. 75p. (Relatório Técnico CNPq).

BRECKE, B. J. Wild poinsettin (Euphorbia heterophylla) germination and emergence. Weed Science, v. 43, p. 103-106, 1995.

BRECKE, B. J.; TOBOLA, P. Growth and developments of Wild poinsettin (Euphorbia heterophylla) selections in peanut (Arachis hypogaea). Weed Science, v.44, p.575-578, 1996. 
DIAS, A.C.R. et al. Problemática da ocorrência de diferentes espécies de capim-colchão (Digitaria spp.) na cultura da cana-de-açúcar. Planta daninha, v. 25, n. 3, p.489-499, 2007.

DUARTE, D. J. et al. Crescimento e nutrição mineral de Ipomoea nil. Planta daninha, v.26, n.3, p. 577583, 2008.

ESPIRONELO, A. Cana-de-açúcar. Recomendações de adubação e calagem para o Estado de São Paulo. 2.ed. Campinas: Instituto Agronômico, p.10, 1992.

FAVRETO, R.; MEDEIROS, R. B. Banco de sementes do solo em área agrícola sob diferentes sistemas de manejo estabelecida sobre campo natural. Revista brasileira de sementes, Pelotas, v. 28, n. 2, p.3444, 2006.

GARCIA, J. C. et al. Association of organic and mineral fertilization on crop yield and theoretical cachaça in sugarcane. Journal of Agricultural Science and Technology, v. 1, p. 38-47, 2011.

GRAVENA, R. et al. Controle de plantas daninhas através da palha de cana-de-açúcar associada à mistura dos herbicidas trifloxysulfuron sodium + ametryn. Planta Daninha, v. 22, p. 419-427, 2004.

HARKER, K. N. et al. Integrating cropping systems with cultural techniques augments wild oat (Avena fatua) management in barley. Weed Science, v.57, n.3, p.326-337, 2009.

KUVA, M.A. et al. Períodos de interferência das plantas daninhas na cultura da cana-de-açúcar: III capim-braquiária (Brachiaria decumbens) e capim-colonião (Panicum maximum). Planta daninha. v.21, n.1, p. 37-44, 2003.

KUVA, M.A. et al. Períodos de interferência das plantas daninhas na cultura da cana-de-açúcar: II capim-braquiária (Brachiaria decumbens). Planta daninha. v.19, n.3, p. 323-330, 2001.

MACHADO, A.F.L. et al. Análise de crescimento de Digitaria insularis. Planta Daninha, v. 24, n. 4, p. 641-647, 2006.

MAGUIRE, J.D. Speed of germination aid in selection and evaluation for seedling emergence and vigor. Crop Science. Madison, v.2, n.2, p.176-177, 1962.

MARTINS, T.A. et. al. Acúmulo de matéria seca e macronutrientes por plantas de Merremia aegyptia. Planta Daninha, v. 28, p.1023-1029, 2010.

MASCARENHAS, M. H. T. et al. Eficácia do halosulfuron no controle de tiririca (Cyperus rotundus) na cultura da cana-de-açúcar. Planta daninha, v.13, n.2, p. 69-80, 1995.

MAULE, R. F; MAZZA, J. A; MARTHA JR., G. B. Produtividade agrícola de cultivares de cana-deaçúcar em diferentes solos e épocas de colheita. Scientia Agrícola, Piracicaba, v. 58, n.2, p.295-301, 2001.

MONQUERO, P.A. et al. Eficácia de herbicidas em diferentes quantidades de palha de cana-de-açúcar no controle de Euphorbia heterophylla. Planta daninha, v.25, n.3, p.613-619, 2007.

O'DONOVAN, J.T. et al. Wild oat (Avena fatua) interference in barley (Hordeum vulgare) is influenced by barley variety and seeding rate. Weed Technology, v.14, n.3, p.624-629, 2000.

OLIVEIRA, I. P. et al. Efeitos de fontes de cálcio no desenvolvimento de gramíneas solteiras e consorciadas. Ciênc. Agrotec. v.33, n.2, p.592-598, 2009.

PANG, L. P. et al. Simulation of picloram, atrazine and simazine leaching through two New Zealand soils and into groundwater using HYDRUS-2D. J. Contam. Hydrol., v.44, n.1, p.19-46, 2000. 
REDDY, M.R., DUNN, S.J. Differential response of soybean genotypes to soil $\mathrm{pH}$ and manganese application. Plant Soil, v.101, n.1, p.123-126, 1987.

RUIZ, M.A., NETO, J.C., SANTANA, J.C. Evaluación preliminar de dos espécies de Brachiaria en Itabela, Bahia, Brasil. Past. Trop., v.17, n.1, p.31-37, 1995.

SILVA, A. A. et al. Efeito residual no solo dos herbicidas imazamox e imazethapyr para as culturas de milho e sorgo. Planta daninha, v.17, n.3, p.345-354, 1999.

SILVA, I. A. B. et al. Interferência de uma comunidade de plantas daninhas com predominância de Ipomoea hederifolia na cana-soca. Planta daninha, v.27, n.2, p. 265-272, 2009.

SOUZA FILHO, A. P. S. et al. Germinação de sementes de plantas daninhas de pastagens cultivadas: Mimosa pudica e Ipomoea asarifolia. Planta Daninha, v.19, n.1, p. 23-31, 2001.

SOUZA FILHO, A. P. S.; VELOSO, C. A. C.; GAMA, J. R. N. Capacidade de absorção de nutrientes do capim-marandu (Brachiaria brizantha) e da planta daninha malva (Urena lobata) em função do $\mathrm{pH}$.

Planta Daninha, v.18, n.3, p.443-450, 2000.

WEAVER, S.E., HAMILL, A.S. Effects of soil $\mathrm{pH}$ on competitive ability and leaf nutrient content of corn (Zea mays L.) and three weed species. Weed Science, v.33, n.4, p.447-451, 1985.

YAMASHITA, O.M. et al. Fatores ambientais sobre a germinação de Emilia sonchifolia. Planta daninha, v.27, n.4, p. 673-681, 2009.

ZHOU, J.; DECKARD, E. L.; AHRENS, W. H. Factors affecting germination of hairy nightshade (Solanum sarrachoides) seeds. Weed Science, v. 53, p. 41-45, 2005. 
Nucleus, v.9, n.2, out.2012 